\title{
Development of a Fluorimetric Sequential Injection Analysis (SIA) Methodology for Determination of Quinine
}

\author{
Carlos M. C. Infante and Jorge C. Masini* \\ Instituto de Química, Universidade de São Paulo, Av. Prof. Lineu Prestes 748, \\ 05508-000 São Paulo-SP, Brazil
}

\begin{abstract}
Desenvolveu-se uma metodologia de análise por injeção sequencial (SIA) para a determinação fluorimétrica de quinino em refrigerantes. Dispersão mínima e mistura eficiente foram obtidas aspirando-se $200 \mu \mathrm{L}$ de amostra entre duas zonas de $100 \mu \mathrm{L}$ de reagente $\left(0,10 \mathrm{~mol} \mathrm{~L}^{-1} \mathrm{H}_{2} \mathrm{SO}_{4}\right)$ a uma vazão de $250 \mu \mathrm{L} \mathrm{s}^{-1}$, usando uma bobina de reação de $50 \mathrm{~cm}$ de comprimento $(0,8 \mathrm{~mm}$ de diâmetro interno). Resposta linear para concentrações (C) entre 0,050 e $100,0 \mathrm{mg} \mathrm{L}^{-1}$ foi descrita por: $\mathrm{I}=(532 \pm 40)+(2,36 \pm 0,04) \mathrm{C}, \mathrm{com} \mathrm{r}=0.999$, onde I é intensidade relativa de fluorescência. Coeficiente de variação e limites de detecção e quantificação foram $1,9 \%\left(0,50 \mathrm{mg} \mathrm{L}^{-1}, \mathrm{n}=10\right), 2,3$ e $4,5 \mu \mathrm{g} \mathrm{L}{ }^{-1}$, respectivamente. A frequência de amostragem foi 60 amostras por hora, consumindo $2,2 \mu \mathrm{L}$ de $\mathrm{H}_{2} \mathrm{SO}_{4}$ concentrado e produzindo $4 \mathrm{~mL}$ de resíduos por análise. Não foram observadas diferenças significativas entre os resultados obtidos pela metodologia SIA proposta e aqueles obtidos pelo procedimento em batelada.
\end{abstract}

A sequential injection analysis (SIA) methodology was developed for fluorimetric determination of quinine in soft drinks. Minimum dispersion and efficient mixing were achieved by aspirating $200 \mu \mathrm{L}$ of sample between two $100 \mu \mathrm{L}$ reagent zones $\left(0.10 \mathrm{~mol} \mathrm{~L}^{-1} \mathrm{H}_{2} \mathrm{SO}_{4}\right)$ at flow rate of $250 \mu \mathrm{L} \mathrm{s}^{-1}$ and using a reaction coil length of $50 \mathrm{~cm}(0.8 \mathrm{~mm}$ internal diameter). Linear response for quinine concentrations (C) between 0.050 and $100.0 \mathrm{mg} \mathrm{L}^{-1}$ was described by: $\mathrm{I}=(532 \pm 40)+(2.36 \pm 0.04) \mathrm{C}$, with $\mathrm{r}=0.999$, where $\mathrm{I}$ is the relative fluorescence intensity. The coefficient of variation and limits of detection and quantification were $1.9 \%\left(0.50 \mathrm{mg} \mathrm{L}^{-1} \mathrm{n}=10\right)$, 2.3 and $4.5 \mu \mathrm{g} \mathrm{L}^{-1}$, respectively. The sampling throughput was 60 analyses per hour, consuming $2.2 \mu \mathrm{L}$ of concentrated $\mathrm{H}_{2} \mathrm{SO}_{4}$ and producing $4 \mathrm{~mL}$ of wastes per analysis. No statistically significant differences were observed between the results obtained by the proposed SIA methodology and the ones obtained by the batch procedure.

Keywords: sequential injection analysis, quinine, fluorimetry, dispersion, optimization

\section{Introduction}

Sequential injection analysis (SIA) is a robust single channel flow technique widely used to automate analytical determinations and process control. It is based on the measurement of a transient signal resulting from sequential injection of defined sample and reagent volumes in a carrier solution under controlled dispersion. ${ }^{1}$ The sample processing conditions can be changed by software control as required by the analytical procedure. The possibility of exploiting feedback mechanisms to change sample processing conditions using a unique physical configuration make these approaches attractive to design flow procedures for process monitoring. ${ }^{2,3}$ The characteristics of SIA

*e-mail: jcmasini@iq.usp.br enable automation of diverse operations such as sampling, chemical derivatization, dilution, standard addition and others, improving the reproducibility. Low sample and reagent consumption and small waste generation ${ }^{4,5}$ are remarkable features of this technique, following the principles of green chemistry ${ }^{6}$ applied to development of clean analytical methods. A typical system is configured in single line by a syringe pump, coupled to a two-way valve that can communicate with the carrier or with a multiport valve through a holding coil where the reaction zone is formed prior to injection toward the detector, placed in another port of the multiport valve, immediately after the reaction coil. ${ }^{7}$ The optimization process can be laborious and take a long time, depending on the chosen route and variables considered in the process. The whole process may be simplified by an initial evaluation of sample dispersion 
and mixing efficiency using a dye solution in place of either sample or reagent. ${ }^{78}$ In SIA systems this approach is useful because the physical configuration does not change, and all the parameters can be used for development of other methods if the tubing dimensions are not altered. As a second step the chemical parameters are optimized for the specific determination, usually considering: concentration of reagents, flow rate, stopped-flow time and others.

The alkaloid quinine $((R)$-(6-methoxyquinolin4-yl)((2S,4S,8R)-5-vinylquinuclidin-2-yl)methanol trihydrate), originally extracted from the Peruvian quina tree (Cinchona), was firstly used as antimalarial. ${ }^{9}$ Diverse uses have been reported: in medicine as antiparasitic, antiprotozoal, anti-arrhythmic, antispasmodic; in cosmetics to decrease hair loss; in drinks as flavor drinks and bitter digestive aid. ${ }^{10}$ Alkaloids are toxic if consumed in large doses; consequently the concentration control is mandatory. The Food and Drug Administration of the United States (FDA) ${ }^{11}$ has established a limit content for quinine in soft drink of $83 \mathrm{mg} \mathrm{L}^{-1}$ and in Brazil the National Health Surveillance Agency (ANVISA) ${ }^{12}$ established the concentration of 30 to $50 \mathrm{mg} \mathrm{L}^{-1}$ of quinine. Diverse procedures are employed for quinine determination, ${ }^{13}$ but the intense fluorescence in acidic medium is a quinine property that is widely used for its quantification..$^{14,15}$ Fluorimetry provides low detection limits and wide linear dynamic range, but its application is restricted because the analyte must be fluorescent or a fluorescent derivate must be produced. ${ }^{16}$ Complex matrixes can be analyzed by high performance liquid chromatography (HPLC) ${ }^{17}$ in normal phase ${ }^{18}$ or based on ion-pair formation, ${ }^{19}$ considering the ionic nature of quinine. But this makes difficult the determination because the equilibrium between mobile and stationary phases is slow and the separation is susceptible to variations of temperature, $\mathrm{pH}$ and concentration of organic compounds in the mobile-phase. For quality control, a quick method that saves sample and reagent, and produces low quantities of waste is highly desirable.

The aim of this work was the development of a fluorimetric sequential injection analysis (SIA) methodology for quinine determination, suggesting a general protocol to start the optimization of SIA systems and applying the procedure for determination of quinine in soft drinks of several trademarks.

\section{Experimental}

\section{Apparatus}

A FIAlab 3500 (FIAlab Instruments, Bellevue, WA) instrument was used in all experiments in the sequential injection mode according to Figure 1. Solutions were driven by a $5.00 \mathrm{~mL}$ syringe pump and an eight port rotary valve (RV, Valco Instrument Co., Houston, TX). The holding coil, $\mathrm{HC}$, was made of $3 \mathrm{~m}$ of $0.8 \mathrm{~mm}$ i.d. polytetrafluoroethylene (PTFE, Teflon ${ }^{\circledR}$, DuPont) tubing. The reaction coil (RC) was $50 \mathrm{~cm}$ long, made of $0.8 \mathrm{~mm}$ i.d. PTFE tubing. All other tubing connections were made of $0.5 \mathrm{~mm}$ i.d. PTFE tubing and PTFE nuts and ferrules (Upchurch, Oak Harbor, WA). The control of the pump and valve was made with the FIAlab 5.0 software. Fluorescence detection was performed with a PMT-FL (FIAlab Instruments) fluorimeter with excitation at $340 \mathrm{~nm}$ (the source of light was an inexpensive LED), measuring the emission at $450 \mathrm{~nm}$ (selected with an interference filter) using a photomultiplier as detector, coupled to a $3.1 \mu \mathrm{L}$ illuminated flow cell. Acquisition data was performed with the FIAlab 5.0 software.

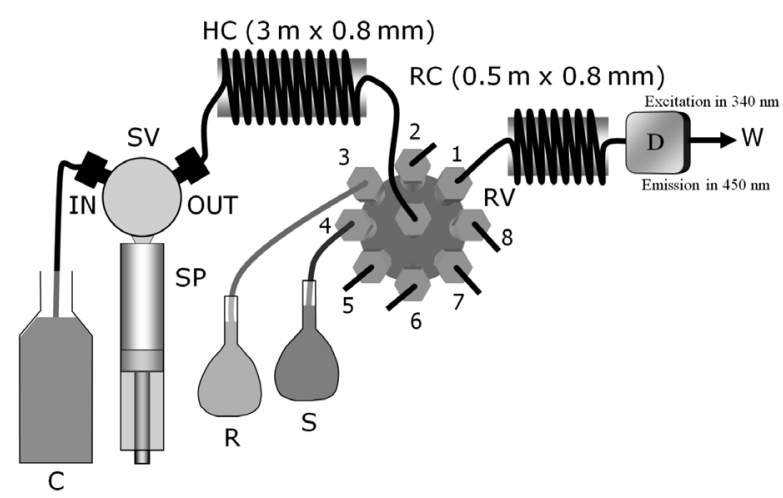

Figure 1. Sequential injection system for determination of quinine: $\mathrm{C}=$ carrier solution $\left(\mathrm{H}_{2} \mathrm{O}\right), \mathrm{SV}=$ syringe valve, $\mathrm{SP}=$ syringe pump, $\mathrm{HC}=$ holding coil, $\mathrm{RV}=$ eight port rotary selection valve, $\mathrm{S}=$ standard solution/sample, $\mathrm{R}=0.10 \mathrm{~mol} \mathrm{~L}^{-1}$ sulfuric acid, $\mathrm{RC}=$ reaction coil, $\mathrm{D}=$ fluorimetric detector and $\mathrm{W}=$ waste.

The dispersion was studied by molecular absorbance spectrophotometry at $620 \mathrm{~nm}$ with a dye solution composed of $0.010 \mathrm{~mol} \mathrm{~L}^{-1}$ bromothymol blue (BTB) in $0.010 \mathrm{~mol} \mathrm{~L}^{-1}$ borate buffer ( $\mathrm{pH} 9.1$ ), using an USB 4000 spectrometer (Ocean Optics, Dunedin, FL, USA) for measurements. A Tungsten-Halogen lamp LS-1 (Ocean Optics, Dunedin, FL, USA) was used as light source with a Hellma U-flow cell with $10 \mathrm{~mm}$ light pathlength and $80 \mu \mathrm{L}$ internal volume. Two optical fibers (600 $\mu \mathrm{m}$ diameter and 20 inches long) were used to transmit radiation from the source to the flow cell and to the spectrometer.

\section{Reagents and solutions}

All solutions were prepared with analytical-grade chemicals and freshly distilled-deionized water. The reagent $(\mathrm{R})$ was prepared by dissolution of concentrated sulfuric acid ( $c$. $18 \mathrm{~mol} \mathrm{~L}^{-1}$ ), making the volume up to 
1.0 L with water. A $1000 \mathrm{mg} \mathrm{L}^{-1}$ quinine stock solution was prepared by dissolution of the sulfate mono-hydrated (Riedel-de-Haën, Seelze-Germany) in water. Working solutions of concentrations between 0.050 and $100.0 \mathrm{mg} \mathrm{L}^{-1}$ were prepared by dilution of the stock solution in water.

Soft drink samples were purchased from a local supermarket and directly analyzed by SIA without any preparation. For the fluorimetric batch methodology the samples were dissolved in $0.050 \mathrm{~mol} \mathrm{~L}^{-1} \mathrm{H}_{2} \mathrm{SO}_{4}$ and properly diluted.

\section{Flow diagram and procedure}

The flow system (Figure 1) is initially filled with carrier solution. To start the automated analyses, the syringe valve is set at position IN and the syringe pump aspirates $4500 \mathrm{~mL}$ of carrier solution inside the syringe at a flow rate of $300 \mu \mathrm{L} \mathrm{s}^{-1}$. Next, the syringe valve switches to position OUT and, with the rotary valve at position 4 , the syringe pump aspirates $500 \mu \mathrm{L}$ of sample; the rotary valve switches to port 2 and the syringe pump dispenses $1000 \mu \mathrm{L}$, cleaning the sample line, preparing the system for the determination. In the next step, the syringe pump stacks sequentially $100 \mu \mathrm{L}$ of the reagent $\mathrm{R}$ (port 3), $200 \mu \mathrm{L}$ of standard or sample $\mathrm{S}$ (port 4), and $100 \mu \mathrm{L}$ of reagent $\mathrm{R}$ (port 3) inside the holding coil at a flow rate of $250 \mu \mathrm{L} \mathrm{s}^{-1}$. In the final step, the rotary valve switches to port 1 and the syringe pump dispenses $2500 \mu \mathrm{L}$ of carrier at $250 \mu \mathrm{L} \mathrm{s}^{-1}$, injecting the mixture zone through the mixing coil and the flow cell of the detector. Simultaneously, the acquisition data system is activated and the transient fluorescence analytical signal is obtained. Next, the flow rate is increased to $450 \mu \mathrm{L} \mathrm{s}^{-1}$ and the syringe is emptied, flushing the system for the next analysis. All measurements were carried out in triplicate.

\section{Results and Discussion}

\section{Sample to reagent volume ratios and dispersion}

Initially the influence of the sample and reagent volumes on the dispersion coefficient (D) was studied with the dye solution using a spectrophotometer. The sequence of aspiration to compose the sample zone was established in the "sandwich" format, with the sample between aliquots of reagent. Diverse volumetric proportions of sample and reagent were tested to define the best compromise between minimal dispersion and efficient mixture. The increase of sample volume (Figure 2A) reduces dramatically the dispersion, but over $200 \mu \mathrm{L}$ no significant variations are observed, since the dispersion coefficient approaches the unity. The increase of reagent volume (Figure 2B) has
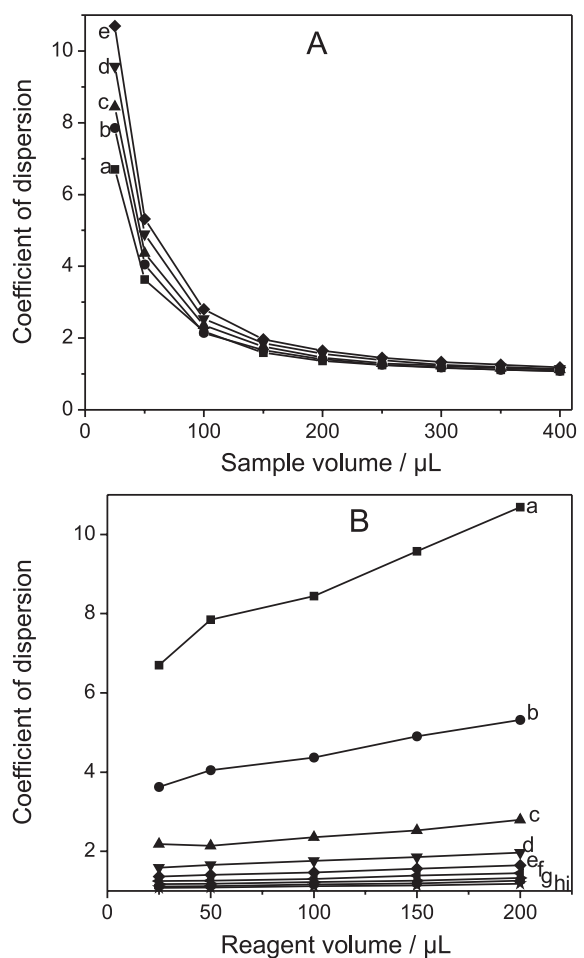

Figure 2. (A) Dispersion coefficients of sample zones as a function of diverse sample volumes sandwiched by reagent volumes of (a) 25 , (b) 50 , (c) 100 , (d) 150 and (e) $200 \mu \mathrm{L}$, and (B) variation of the dispersion coefficients of sample zones formed by injecting (a) 25, (b) 50, (c) 100 , (d) 150 , (e) 200 , (f) 250 , (g) 300 , (h) 350 and (i) $400 \mu \mathrm{L}$ of sample between two reagent zones formed by reagent volumes varying from 25 to $200 \mu \mathrm{L}$.

significant influence on sample dispersion only for sample volumes $<100 \mu \mathrm{L}$.

Reagent-based chemistries automated by sequential injection analysis require the identification of the time interval in which sample and reagent zones are mutually interdispersed, a condition that is achieved for D $>2$ if, at the same time, sufficient excess of reagent is present. ${ }^{7}$ Increase in sample volume enhances the sensitivity of the measurements only if excess of reagent is fed to the sample zone. Thus, for sample volumes as large as the ones leading to $1<\mathrm{D}<2$, sandwiching the sample between reagent zones is recommended. Additionally, under these conditions it is recommended to use reagents with concentration larger than that ones used in flow injection systems configured with confluence points. Figure 3 shows the gradient profile of reagent and sample zones for a method configured by sandwiching different sample volumes between $100 \mu \mathrm{L}$ reagent zones. Complete interdispersion is achieved for sample volume of $25 \mu \mathrm{L}(\mathrm{D}>6)$ as shown in Figure 3A, but at the cost of low sensitivity of the measurement as a consequence of the large degree of sample dilution. With a sample volume of $200 \mu \mathrm{L}$ (Figure 3B), it is still possible to feed reagent to the sample zone using the sandwich approach, but one must be careful preparing a sufficiently 

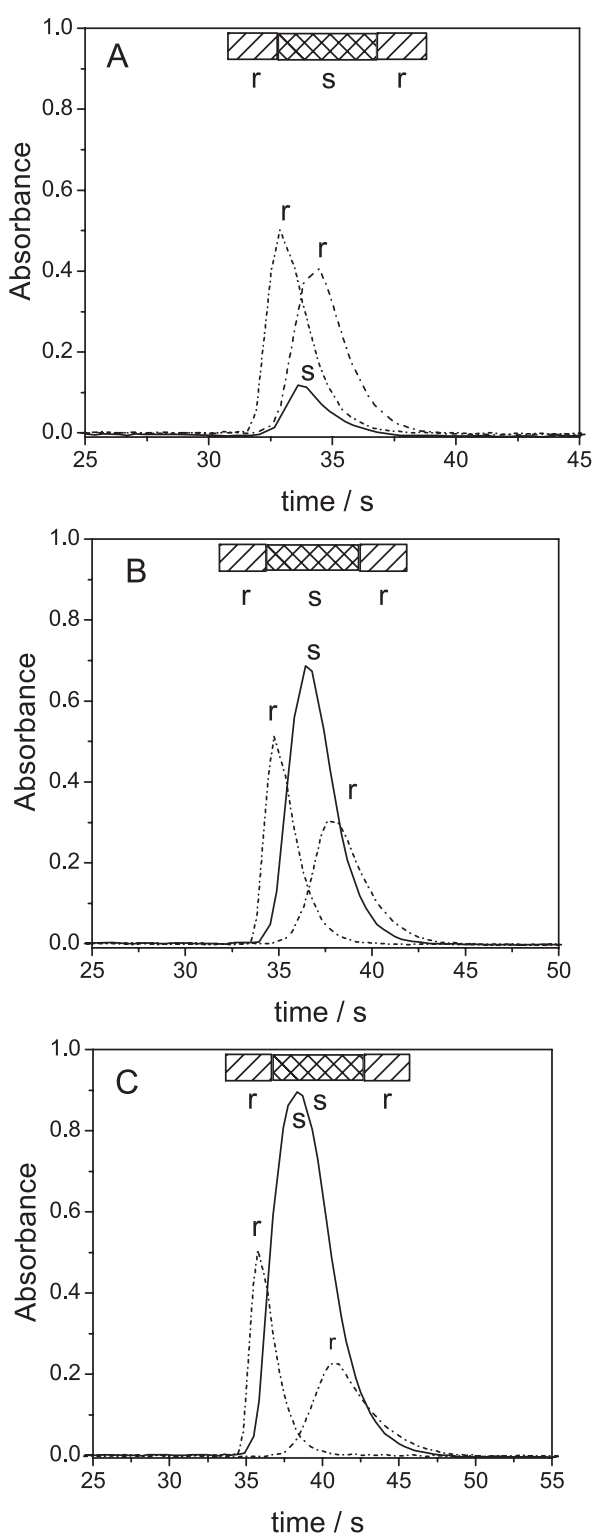

Figure 3. Interpenetration of sample (S) and reagent (r) zones using two $100 \mu \mathrm{L}$ reagent zones sandwiching (A) $25 \mu \mathrm{L}$, (B) $200 \mu \mathrm{L}$ and (C) $400 \mu \mathrm{L}$ of sample. In this case the transient signal is caused by a $0.01 \mathrm{~mol} \mathrm{~L}^{-1}$ BTB solution injected either as reagent or sample, using the $0.010 \mathrm{~mol} \mathrm{~L}^{-1}$ borate buffer as carrier.

concentrated reagent to warrant its excess in the central portions of the reaction zone. Increasing the sample volume further to $400 \mu \mathrm{L}$ (Figure 3C) is no longer recommended because the reaction will occur only in the edges of the sample zone, which will cause peak distortions leading to inaccuracy in the results, besides to increased sample consumption and decreased the sampling throughput.

\section{Influence of the chemical and hydrodynamic parameters}

The formation of fluorescent species was carried out in acid media, a condition in which the quinine molecule is rigid and the not radioactive deactivation is less likely. The spectrum of quinine in this condition indicates the presence of two intense maximum of excitation at 280 and $350 \mathrm{~nm}$, the latter wavelength being chosen because it is easily implemented with a LED. The maximal emission is observed in $450 \mathrm{~nm}$, and was monitored with the aid of an interference filter. Formation of the fluorescent species with sulfuric acid is slow, but the product is highly stable and the quenching effect of chloride ions is avoided.

The evaluation of the experimental conditions was carried out by the univariate method. As expected, increase in the concentration of sulfuric acid (Figure 4A) enhanced the signal, without causing Schlieren effect, ${ }^{20}$ which is likely to occur in case of spectrophotometric detection. A sulfuric acid concentration of $100 \mathrm{mmol} \mathrm{L}^{-1}$ was elected, considering the little increase in the signal observed for higher concentrations. The influence of the sample volume (sandwiched between two $100 \mu \mathrm{L}$ zones of $100 \mathrm{mmol} \mathrm{L}^{-1} \mathrm{H}_{2} \mathrm{SO}_{4}$ ) is shown in Figure 4B. The analytical signal increased with the sample volume, but the volume of $200 \mu \mathrm{L}$ was selected to avoid the problems discussed in the previous section, related to lack of sulfuric acid in the central portion of the sample volume. Besides,
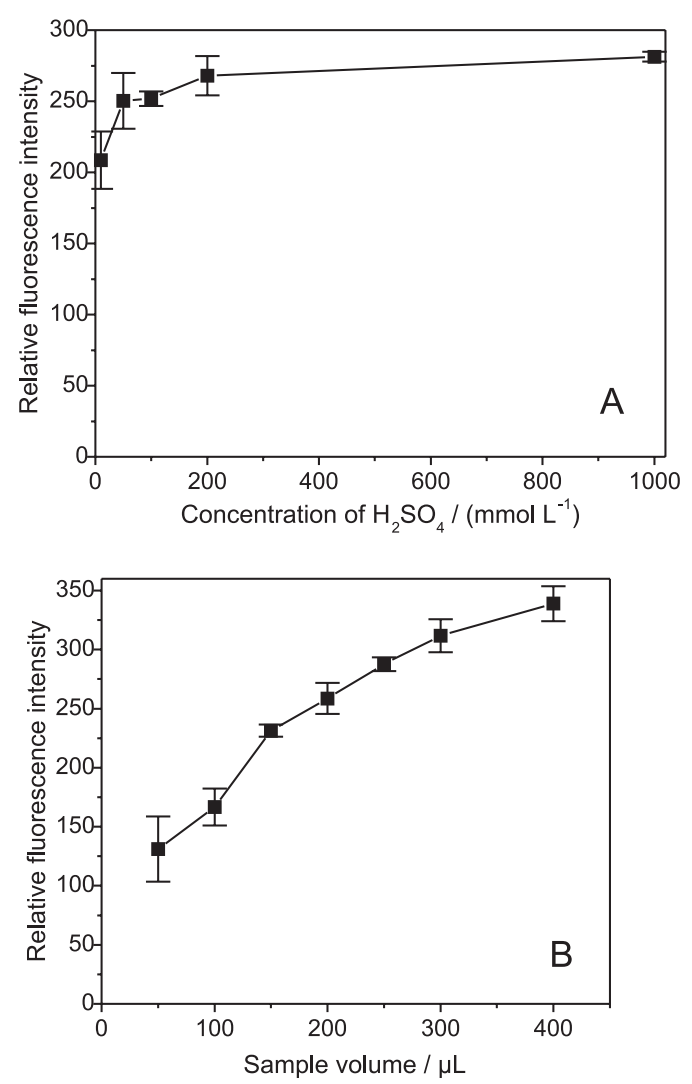

Figure 4. Evaluation of reaction conditions: (A) variation of analytical signal as a function of concentration of reagent; quinine concentration $50 \mathrm{mg} \mathrm{L}^{-1}$, and (B) variation of analytical signal as a function of sample volume; $\mathrm{H}_{2} \mathrm{SO}_{4}$ concentration $0.10 \mathrm{~mol} \mathrm{~L}^{-1}$ 
sample volumes larger than $200 \mu \mathrm{L}$ imply in high sample consumption and significant decrease in the sampling throughput. The influence of the residence time on the analytical signal was studied by varying the flow rate in the range from 50 to $400 \mu \mathrm{L} \mathrm{s}^{-1}$ and the reaction coil length (30, 50 and $100 \mathrm{~cm}$ ). These parameters did not have significant influence on the analytical signal, indicating the reaction is fast and is completed in the time scale of the experiments. Flow rate of $250 \mu \mathrm{L} \mathrm{s}^{-1}$ and reaction coil of $50 \mathrm{~cm}$ were selected to obtain a high sampling throughput, providing quick clean-up of the system after the determination.

\section{Figures of merit}

Linear response was observed for quinine concentrations between 0.05 and $100.0 \mathrm{mg} \mathrm{L}^{-1}$ as quinine sulfate, described by the equation: $\mathrm{I}=(532 \pm 40)+(2.36 \pm 0.04) \mathrm{C}$ with $\mathrm{r}=0.999$. The detection limit was estimated at $2.3 \mu \mathrm{g} \mathrm{L}-1$ at the $99.7 \%$ confidence level. Sampling rate and coefficient of variation $(n=10)$ were estimated at 60 measurements per hour and $1.9 \%$, respectively. The proposed procedure consumed the equivalent to $2.2 \mu \mathrm{L}$ of concentrated sulfuric acid, which was 322 -fold lower than the consumption in the batch procedure. ${ }^{15}$ The effluent volume was $4.0 \mathrm{~mL}$ per determination, which was 64 -fold lower than the consumption in the batch procedure. ${ }^{15}$ Comparison of the reagent consumption with other procedures is difficult in view of the use of other reagents ${ }^{13}$ and solvents in chromatographic separation. ${ }^{19}$ However the proposed procedure can be considered a green analytical method in view of the consumption of low amounts of low toxicity reagents.

\section{Selectivity}

The main interference in the fluorimetric determination of quinine is related with vitamin $\mathrm{B}^{18}$ and other alkaloids of similar structure. ${ }^{19}$ In the case of soft drinks, it is not expected the presence of any other alkaloid and the quinine concentration is high, so the possible interference of vitamin B is negligible. Other interesting aspect in the flow-based procedure in view of the low residence time ( $c a .30 \mathrm{~s}$ ) is the minimization in the extension of side reactions, improving the selectivity. ${ }^{21}$

\section{Analysis of samples}

The proposed procedure was applied for quinine determination in soft drinks of all the commercially available trademarks in Brazil. Quinine concentrations found in all samples were smaller than the limit value established by $\mathrm{FDA}^{11}$ (108 $\mathrm{mg} \mathrm{L}^{-1}$ as quinine sulfate), but in two cases these concentrations exceeded the limit defined by ANVISA ${ }^{12}$ (65 $\mathrm{mg} \mathrm{L}^{-1}$ as quinine sulfate). Table 1 shows that there is no evidence of statistically significant differences between the results obtained by the SIA procedure and those ones obtained by the fluorimetric batch reference procedure ${ }^{15}$ at the $95 \%$ confidence level, by considering a paired student's $t$-test $(\mathrm{n}=8)$. Other profitable characteristics are the possibility of direct determination of quinine, without prior dilution, and reduction of the analyses time ( $c a .1 \mathrm{~min}$ ), in comparison with about $5 \mathrm{~min}$ required for batch procedures.

Table 1. Quinine determination in soft drink water samples

\begin{tabular}{lcc}
\hline \multirow{2}{*}{ Sample } & \multicolumn{2}{c}{ Quinine concentration $/\left(\mathrm{mg} \mathrm{L}^{-1}\right)^{\mathrm{a}}$} \\
\cline { 2 - 3 } & Proposed procedure & Batch procedure \\
\hline Classic lemon & $54.2 \pm 0.6$ & $52.7 \pm 0.3$ \\
Antartica & $53.9 \pm 0.3$ & $54.2 \pm 0.4$ \\
Antartica light & $54.9 \pm 0.2$ & $51.8 \pm 0.3$ \\
Classic light & $50.3 \pm 0.2$ & $50.2 \pm 0.8$ \\
Classic & $61.3 \pm 0.3$ & $60.7 \pm 1.2$ \\
Schweppes light & $66.3 \pm 0.3$ & $63.5 \pm 0.5$ \\
Schweppes & $59.6 \pm 0.2$ & $62 \pm 2$ \\
Schin & $66.2 \pm 0.7$ & $66 \pm 2$ \\
Prata & $80.5 \pm 0.4$ & $80 \pm 3$ \\
\hline
\end{tabular}

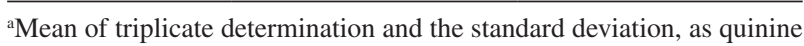
sulfate.

\section{Conclusions}

The sequential injection analysis methodology shows profitable characteristics for the determination of quinine in soft drinks. Optimization is simple and is started by searching the sample to reagent volumetric ratio that provides efficient mixture and low dispersion. Sensitivity was improved by using a fluorimetric determination yielding a linear response range compatible with diverse requirements (e.g. the established by the US-FDA ${ }^{11}$ or ANVISA). ${ }^{12}$ Sampling throughput was improved (60 samples per hour) and reagent consumption was at least 322 -fold reduced in relation to previous works ${ }^{15}$ as a consequence of the use of intermittent flow. The proposed procedure can be considered as a clean alternative for fast quinine determination in soft drinks.

\section{Acknowledgements}

The authors acknowledge the fellowships and financial support from the Conselho Nacional de Desenvolvimento Científico e Tecnológico (CNPq) and from the Fundação 
de Amparo à Pesquisa do Estado de São Paulo (FAPESP, grant 2008/09284-3).

\section{References}

1. Ruzicka, J.; Marshall, G. D.; Anal. Chim. Acta 1990, 237, 329.

2. Mesquita, R. B. R.; Rangel A. O. S. S.; Anal. Chim. Acta 2009, $648,7$.

3. Mervartová, K.; Polásek, M.; Martínez Calatayud, J.; J. Pharm. Biomed. Anal. 2007, 45, 367.

4. Economou, A.; TrAC, Trends Anal. Chem. 2005, 24, 416.

5. Cerdà, V.; Cerdà, A.; Cladera, A.; Oms, M. T.; Mas, F.; Gómez, E.; Bauzá, F.; Miró, M.; Forteza, R.; Estela, J. M.; TrAC, Trends Anal. Chem. 2001, 20, 407.

6. Anastas, P. T.; Kirchoff, M. M.; Acc. Chem. Res. 2002, 35, 686.

7. Gubeli, T.; Christian, G. D.; Ruzicka, J.; Anal. Chem. 1991, 63, 2407.

8. Masini, J. C.; Quim. Nova 2008, 31, 704.

9. Samuelsson, G.; Drugs of Natural Origin, $5^{\text {th }}$ ed.; Swedish Pharmaceutical Press: Stockholm, 1992.

10. Papariello, G. J.; Tishler, F. In Encyclopedia of Industrial Chemical Analysis; Snell, F. D.; Hilton, C. L., eds.; Interscience Publishers: New York, 1967, chapter 4.

11. http://www.fda.gov/Food/FoodIngredientsPackaging/ FoodAdditives/ucm191033.htm accessed in January 2011.
12. http://www.anvisa.gov.br/legis/decretos/2314_97.htm accessed in January 2011.

13. Ortega-Algar, S.; Ramos-Martos, N.; Molina-Díaz, A.; Microchim. Acta 2004, 147, 211.

14. Guilbault, G. G.; Practical Fluorescence: Theory, Methods and Techniques, $1^{\text {st }}$ ed.; Marcel Decker: New York, 1973.

15. O’Reilly, J. E.; J. Chem. Educ. 1975, 52, 610.

16. Ruzicka, J.; Hansen, E. H.; Flow Injection Analysis, $2^{\text {nd }}$ ed.; Wiley Interscience: New York, 1988.

17. Gatti, R.; Gioia, M. G.; Cavrini, V.; Anal. Chim. Acta 2004, 512,85 .

18. McCalley, D. V.; J. Chromatogr., A 1983, 260, 184.

19. Chen, Q. C.; Wang, J.; J. Liq. Chromatogr. Relat. Technol. 2001, $24,1341$.

20. Zagatto, E. A. G.; Arruda, M. A. Z.; Jacintho, A. O.; Mattos, I. L.; Anal. Chim. Acta 1990, 234, 153.

21. Infante, C. M. C.; Soares, V. R. B.; Korn, M.; Rocha, F. R. P.; Microchim. Acta 2008, 161, 279.

Submitted: March 1, 2011

Published online: July 26, 2011

FAPESP has sponsored the publication of this article. 